\title{
Ethnocultural transference and countertransference in psychodynamic psychotherapy in the Netherlands
}

\author{
Wouter Gomperts \\ Psychotherapie-Wissenschaft 8 (2) 46-49 2018 \\ www.psychotherapie-wissenschaft.info \\ CC BY-NC-ND \\ https://doi.org/10.30820.08
}

\begin{abstract}
In recent years, members of non-Western ethnic minorities in the Netherlands have increasingly received psychodynamic psychotherapy, up to now usually from native Dutch therapists. All the ordinary mental problems and common components of psychodynamic therapy can then acquire somewhat different contents and significance. This article is on ethnocultural transference and countertransference in the therapeutic relationship between secondgeneration post-migration patients with a non-Western background and native Dutch therapists.
\end{abstract}

Key-Words: psychodynamic psychotherapy, transcultural psychotherapy, migration, transference and countertransference

\section{The racialization of the self}

Aziza is 29 and has a Moroccan background. Her father came to the Netherlands as a migrant worker. Aziza is born in Morocco. From age four she grew up in the Netherlands. At the psychotherapy intake interview, she talks about how Dutch kids used to make fun of her at school. She had henna on her hands and her parents were traditionally dressed.

«Two Dutch girls who were really losers were the only ones who would sometimes play with me. The isolation was so awful that the teacher decided the kids had to take turns playing with me. It was like alms that in a way I was too proud for but was still happy with so I simply accepted the humiliation that went with it. As a child, you are embarrassed about where you come from. At school because my mother was wearing a hijab and could hardly speak Dutch and the food we ate was weird.»

From early childhood onward, second-generation patients have often witnessed their parents being humiliated by individuals and official agencies. As Aziza puts it,

«I was the bridgehead for the family, I had to read documents and write letters and be the interpreter, and that way I got to hear things I would have preferred not to hear. Like in the hospital when they were talking about my mother, Why do those guest workers have to keep having children?»»

Feelings of inferiority and superiority can start in the small world of family interaction, but also have to do with power relations in the larger world of society. From early childhood onward, our sense of self and identity is shaped by how significant others at home or at school think and feel about ethnicity and skin colour, which is related in turn to the significance of these categories at a certain time and place. For generations, white children learned that black people were inferior to them. They learned this as automatically as they learned that trees are made of wood. From one generation to the next, positive or negative emotional associations regarding specific categories of people are included in the implicit memory system via repeated imprinting and conditioning. This helps create a racialized sense of self in white as well as black people, in patients as well in therapists. ${ }^{1}$ Society is in the mind and its past is in the present. A patient with a Caribbean background puts it as follows.

«It has not disappeared. It is active. Why? The closer you are to the Dutch norm, physically or mentally, the better you are. The further you are from the Dutch norm, the more inferior you are. It is inside you, in your mind and in your heart. It has been internalised for generations. People think they are ugly and stupid and primitive, and they have a wide nose and thick lips and bad hair and the wrong colour. And they would love to marry a white person, they would kill to be able to do that. Because then they would get better children, with the better colour. With better chances in life. That is how we have been trained!»

\section{Ethnocultural transference and countertransference}

Altman (2004) notes that the dynamics of the larger society inevitably are manifest in intrapsychic dynamics,

1 See for a psychoanalytic study of internal racism Davids (2011), and for a review of social psychological research on implicit racism Weston (1999). 
as well as interpersonal interactions, in and out of the consulting room. If from childhood your ethnicity is often approached in a negative way in direct contacts, in public opinion, in children's and history books etcetera, it can evoke deep feelings of inferiority, shame, fear and rage. Members of a minority can often be very sensitive to even the slightest sign of discrimination. Applying for psychotherapy activates the attachment system, reinforcing an awareness of social discrimination. Does the therapist see you as a person and not as an example of a problematic minority? Do you get the same opportunities for treatment as a Dutch person? When you register for therapy, there is always the possibility of social stereotyping and discrimination. In that sense, the therapist, intake team and health clinic can be an object of transference and there can also be countertransference. What can happen?

\section{A transference-countertransference enactment during the intake}

Aziza applies for therapy at an outpatient Amsterdam mental health clinic. At a therapy session, she later says, "Anything less than the very best is unacceptable to me. It really has to do with the fact that I grew up Moroccan here in the Netherlands.» At primary school for example, her teachers advised her to attend a simple four-year secondary school. Now she is working at a high level in the field of management. Due to her fear of not getting the treatment she deserves, at the intake interview she is already standing her ground. The therapist finds her a bit aggressive. Her behaviour feels suspicious, intimidating and transgressive, and irritates the therapist, perhaps also because his own natural experience of being in the mainstream Dutch majority position fails to give him much familiarity with and sensitivity to people like Aziza and her type of behaviour in a situation of assessment and selection.

A consequence of the therapist's irritation is that Aziza stands her ground even more and the therapist feels even more annoyed and so on. His growing irritation makes the therapist less able to use his psychoanalytical stance of empathy and understanding and he reverts back to his basic diagnostic skills as a psychiatrist or clinical psychologist. Aziza's behaviour is subsequently seen as a sign of serious personality pathology (paranoid, borderline, narcissistic). This is why Aziza's therapy prognosis at first is assessed as rather poor, which is a self-fulfilling prophecy.

This ethnocultural transference-countertransference enactment fails to devote attention to the fact that Aziza's behaviour and the therapist's reaction to it - and vice versa - can also be related to the macro-level tension in society between emancipating newcomers/outsiders and the established Dutch majority. Transference and countertransference in the consulting room can be manifestations of large-scale societal tension (Leary, 2000). Insufficient acknowledgement of this can mud- dle the diagnostic judgment and give rise to excessive psychiatrization.

Something similar can also occur in another way. Based on his own personal or societal disadvantages, for instance as the youngest sibling or black sheep in the family, as a woman, homosexual or villager in a big city, or his lower social class background or ethnic minority position, the therapist can feel a strong identification with the outsider position of a post-migration non-Western patient. For instance, Aziza's behaviour at the intake interview might be interpreted as the vitality of a spirited immigrant. In the case of strong culturalization, the severity of a patient's pathology can be underestimated. The therapy can subsequently prove disappointing. Excessive psychiatrization and culturalization are both pitfalls in ethnocultural countertransference.

\section{Society in the mind, the past in the present}

In modern Western society, ethnocultural differences can have a strong emotional aspect. With echoes of slavery, colonialism and the Holocaust still reverberating, discriminatory behavioural tendencies are coming up against the restrictive effects of shame and guilt feelings maybe more than ever before, at any rate in right-minded people. Due in part to the fear of racism and discrimination also felt by the therapist as a right-minded Dutchman, there is a great deal of caution in the therapeutic relation when approaching ethnocultural differences. As one supervisee says, «I think it is a touchy issue to approach in therapy. I would immediately get the feeling hey do I think I am so superior? And that is definitely not what I want to be.» If the therapist belongs to the established majority and the patient to a discriminated minority, there can be a defensive interaction between the two that keeps the subject outside the consulting room. The two of us know there is discrimination, but it does not exist between us, we are above all that. This kind of narcissistic collusion can reinforce a patient's anxiety. After all, the unconscious message can be that the therapist does not dare approach the subject, so apparently he might otherwise make some comment indicative of a discriminatory attitude. Both of them know this would mean the end of the patient's trust in the therapist, so they don't say anything at all.

Sometimes, if the therapist belongs to a minority too, the patient looks for and emphasizes the similarity in their backgrounds. A sense of solidarity and a shared destiny can magnify the connectedness with the therapist, sometimes allowing negative feelings about the majority group to be expressed in a more or less covert way. As one patient puts it,

«I wonder if it is all right to ask you something. Your name isn't Dutch, is it? And you have those dark eyes and dark eyebrows and you are so nice, I thought right away you aren't really Dutch either.» 


\section{Exploration of ethnocultural diversity in the therapeutic relationship}

Smith (2006) notes that if the therapist and patient differ in their ethnicity, there is always an awareness of it in the consulting room. So the question is not whether the difference in ethnicity is significant or not, but when to devote attention to it and how to explore its meanings.

Aziza mentions during a therapy session that she went to see Astrid's new baby with her sister. Astrid is a friend of her sister's. Astrid is a common Dutch Christian name. The therapist notes his own focus on the fact that the patient mentions Astrid by name, but continues to refer to her own sister, whom she often talks about in therapy, as my sister. He explores what this can mean.

«Therapist: You just mentioned Astrid by name. But you don't do that when you talk about your sister. Is that right?

Patient: That's true ...

Therapist: Do you have any thoughts about that? Patient: It's automatic ... yes ... I don't really know. Therapist: You don't know?

Patient: In the Netherlands they have a hard time remembering her name.

Therapist: How does that make you feel?

Patient: Not too bad ... But if I know someone longer, then I actually do mind.

Therapist: I have known you for quite some time.

How would it make you feel if I couldn't remember her name?»

Aziza relates that if the therapist would not remember her name or would mispronounce her name, and would continue to do so, she would be disappointed. She says:

\begin{abstract}
«From early childhood onward, I have always tried to be not different from other Dutch people. But I keep noticing, I am still a foreigner. I am often seen as part of the Moroccan problem group. It makes me feel humiliated and really angry. If you labeled me Moroccan, I wouldn't be able to talk to you about deep things any more. I have to assume you can understand this, otherwise I can't do the therapy.»
\end{abstract}

At the following sessions, Aziza expresses her pent up rage and anxiety about the small and sometimes larger confrontations with discriminating stereotypes in her daily life. In therapy, she also experiences these emotions with her therapist. It is important that the therapist is able to tolerate being identified with the discriminating aggressor. The therapist examines his countertransference for his responses to the discriminating micro-aggression the patient attributes him with and traces of discrimination in his own feeling states.

Aziza perceives that her assumptions are not dismissed as being oversensitive, as often happens in daily life. She can now think, feel and speak with greater freedom and acceptance about her ethnocultural identity, the therapist's and other people's ethnocultural identity. Fixed emotional convictions like All Dutch people discriminate and That doesn't happen here at therapy are replaced by greater subtlety and differentiation. Then it can also become clear that the fear of discriminating stereotypes sometimes conceals a different kind of fear. In Aziza's case for example, the fear of emotional closeness and dependence emerges in the transference.

A not-knowing stance means the therapist keeps reminding himself he cannot know a priori what is going on in the patient's mind. This is particularly the case in the event of ethnocultural differences between the patient and the therapist. The therapist should always bear in mind that he can only in part emotionally comprehend a world perceived from a different ethnocultural perspective. Sometimes a therapist can deal with a fear not-knowing might lead to, a fear closely linked to a fear of strangers, by reading extensively about other cultures and asking the patient numerous questions. With this countertransference reaction, the therapist can hope to avoid exhibiting a lack of empathy.

A psychodynamic perspective emphasizes a different approach. Faltering in the relationship due to imperfect therapist empathy with the patient's experiential world is inevitable in every therapy, no matter who the therapist is and who the patient is. The restoration that follows is viewed as an active ingredient essential to the therapy. If a therapeutic alliance falters after the therapist's failure to understand the patient's ethnocultural experiential world, the restoration of the alliance can have special therapeutic value. It demonstrates the possibility of repair and serves as an opportunity to explore and comprehend the ethnocultural misunderstanding in an emotionally meaningful way.

\section{Whiteness can be a countertransference blind spot}

The term whiteness refers to the complacency automatically experienced by white people who fail to reflect on the meaning of their ethnocultural position and have very little empathy with the position of other categories of people or ability to imagine what it can be like. Whiteness can be a countertransference blind spot (Altman, 2000).

The therapist's sensitivity to the possible impact of his specific ethnocultural position on patients with a different background is reinforced by a deeply felt awareness of his own ethnocultural place in society in light of his family history as well as in a wider socio-historical perspective. Training therapy is a requirement for a Dutch post-M.A. degree in psychotherapy and can be helpful in this connection. I am nonetheless afraid little attention is devoted to this theme in the numerous cases where the therapist-in-training and the training therapist both belong to the native Dutch majority and neither of them feels an inner urge to explore the issue. This pitfall is an extra reason to focus on this topic in the psychotherapy curriculum. 


\section{A final remark}

In modern Western society, ethnocultural differences are frequently either stubbornly ignored or expressed in a crude way. For more than a century, therapy professionals have been looking for better ways to cope with difficult emotions than by sweeping them under the carpet or addressing them head on in a coarse way. In the era of Sigmund Freud, difficult impulses and emotions mainly involved sexuality and aggression (Freud, 1961 [1930]). In today's consulting room, ways are sought to deal with ethnocultural diversity in a bolder and more natural manner. This requires a high level of empathy and social imagination on the part of the therapist. If this is difficult for a therapist trained in self-reflection, and reflection on the other person and the relationship between them, it is even more understandable that it should be problematic in the larger world of society. The stronger the regressive and primitive forces in a society for whatever reason, the more alienated larger numbers of people will be from their thoughtful and empathetic side, and the more different segments of the population will be driven away from each other.

Translated from Dutch by Sheila Gogol

\section{Literature}

Altman, N. (2000). Black and white thinking: A psychoanalyst reconsiders race. Psychoanalytic Dialogues, 10, 589-606.

Altman, N. (2004). History repeats itself in transference. Psychoanalytic Dialogues, 14, 807-815.
Davids, F. M. (2011). Internal racism: A psychoanalytic approach to race and difference. Basingstoke: Palgrave Macmillan.

Freud, S. (1961 [1930]). Civilization and its discontents. In The Standard Edition of the Complete Psychological Works of Sigmund Freud. Volume XXI (pp. 64-145). London: The Hogarth Press.

Leary, K. (2000). Racial enactments in dynamic treatment. Psychoanalytic Dialogues, 10, 639-653.

Smith, H.F. (2006). Invisible racism. Psychoanalytic Quarterly, 75(3), 3-19.

Westen, D. (1999). The scientific status of unconscious processes: Is Freud really dead? Journal of the American Psychoanalytic Association, 47, 1061-1106.

\section{The Author}

Wouter Gomperts Ph.D. is a clinical psychologist, psychotherapist and psychoanalyst. He is a training psychoanalyst of the Dutch Psychoanalytic Society and supervisor of the Dutch Society for Psychoanalytic Psychotherapy and a training therapist and training supervisor of the Dutch Society for Psychotherapy. In 2017-2019 he teaches psychoanalysis at the Institute for Interdisciplinary Studies of the University of Amsterdam. He was assistant professor at the Department of Clinical Psychology at the same university (1979-2016) and member of staff of the Dutch Psychoanalytic Institute (19872015). He works in private practice in Amsterdam.

\section{Contact}

Conradstraat $423 \mathrm{G}$

1018 NE Amsterdam

The Netherlands

w.j.gomperts@me.com 